\title{
Designing Footwear for Uniformed South African Females - A Practical Study
}

\author{
Karen BREDENKAMP \\ ERGOnomics TECHnologies, Centurion, South Africa \\ http://dx.doi.org/10.15221/13.467
}

\begin{abstract}
The main challenge inherent in designing for uniformed members remains the accommodation of large variances in anthropometry. Due to the rigid sizing rules characteristic to the footwear industry, designing to accommodate large foot shape variances requires out-of-the-box thinking. The aim of this study was to design female court shoes for uniformed members of the immensely diverse South African (SA) female population. Three dimensional (3D) foot anthropometry was collected for SA females by use of an InFoot ${ }^{\mathrm{TM}}$ laser foot scanner. The foot shapes characteristic to the SA female population were analysed by means of two techniques : 1) principal component analysis (PCA) of 13 foot measurements extracted from the 3D foot data, and 2) PCA of all 3D points on foot scans converted to homologeous 3D foot models $(\mathrm{Di}+)$. The most prominent foot shape variances observed (irrespective of foot length) included foot width and height, heel to ball of foot width ratio and arch height. In addition, the 3D shape analysis (homologeous foot models) highlighted toe box shape, heel shape and heel bone angle variances. The process of designing and developing female court shoes that will incorporate these foot shape variances included several iterations of last design changes and objective fit evaluations. The original last design was conducted by use of Computer Aided Design (CAD) last design software (Shoemaster $^{\mathrm{QS}}$ Custom software) incorporating Cases of 3D foot forms identified to represent the ranges of variances in SA female foot forms. Objective and subjective fit evaluations were conducted on the base size (most popular size). Modifications were made to the last dimensions and shoe construction based on findings of the fit evaluations. A larger scale fit evaluation was conducted incorporating a full size range of the modified court shoe, together with the addition of another court shoe integrating style characteristics more appealing to the user population. The outcome of this fit evaluation highlighted that, although the court shoe provided acceptable accommodation for a large percentage of the SA females, certain foot form variances were not accommodated sufficiently. Currently, the largest design challenge remains with the accommodation of females with flat feet (very low arch heights), broad heels and inverted heel bones. The prevalence of females with very low arch heights was roughly $50 \%$ of the females included in the large scale objective and subjective fit evaluation.
\end{abstract}

Keywords: characterization, foot shapes, last, homologous body modelling, principal component analysis, female footwear

\section{Introduction}

Fairy tales guide us to believe that the female foot shape is uniformly petite and a scaled-down version of the male foot. Numerous studies have however illustrated that this is not the case $[6,7,12,13,5]$.

Consistent with the pre-conceived perception of the female foot shape, the female court shoe remains one of the most challenging in footwear design. The shoe characteristics inherent to the court shoe design focusses on style and appearance stereotypes and does not lend itself to accommodating large variances in foot shape, especially for females with heftier, broader foot shapes. Also, the design of footwear for a uniformed population requires accommodation of all foot size and shape variances in one shoe design where with commercial designs the best style to suit the foot shape can be selected.

In order to design lasts and shoes for uniformed females, foot shapes and sizes were characterised. Three dimensional (3D) foot data was collected for South African (SA) females, starting in $2007 . \quad$ Two analyses approaches were utilised with which the foot shapes were investigated and characterised. The first technique involved the use of the multivariate statistical analysis technique, principal component analysis (PCA), on 13 foot measurements extracted from 3D foot scans. This technique is widely used in the analysis of anthropometric data for application in design [4, 10, 16, 3, 9, 8, 2, 13]. Due to this technique being based on measurements extracted from the 3D foot data, some shape variances were not represented in the analyzed results. A second technique was used which 
incorporated software called Di+ and HBS ((Digital Human Research Centre (DHRC), Japan)) which involved creating homologous foot models for each 3D foot scans and conducting PCA using the 3D point data. The homologous models consisted of an exact replica of the foot scan, but with a set number of data points.

The most prominent variances in SA female foot forms derived from the first analysis method (PCA using measurements extracted from 3D foot data) could be described by 3 factors (Bredenkamp and Skelton, 2009). The first factor describe the overall foot width and height (including foot measurement variables normalized ball girth, foot breadth, instep girth, ball girth height and instep height). The variances in foot shapes are illustrated in Figure 1. The second factor described the arch height variances of the female feet. This is characterized by foot anthropometric variables: navicular-instep ratio, navicular height and medial malleolus height. These variances are illustrated in Figure 2. The third factor describe the third largest dominant foot form variance; the heel-ball foot width ratio and is illustrated in Figure 3.
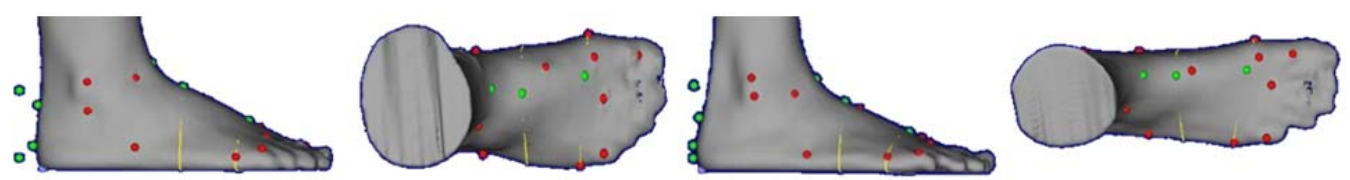

Fig.1 : Side and top views of principal component (PC) 1 high height and wide foot width vs low height and narrow foot width.
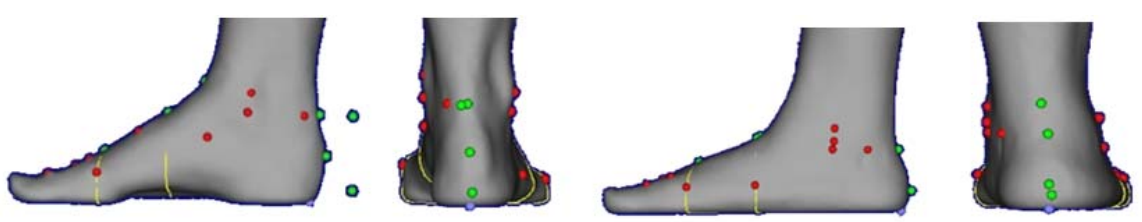

Fig. 2 : Second PC illustrating high arch height and narrow heel vs. low arch height and wider heel.
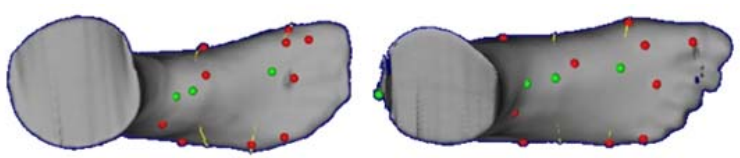

Fig. 3 : Third PC illustrating large ration between heel and ball foot widths vs. smaller ratio between heel and ball foot widths.

The second analysis technique (PCA of 3D point data from homologous foot models), highlighted additional foot shape variances characteristic in the SA female population.

The variances described by the strongest (first) principal component included (in additional to variances described under figures 1 to 3 above) toe box shape (relationship of first three toes) (illustrated in Figure 4). The second strongest PC indicated heel shape variances (see Figure 5). The third PC illustrated variances in calcaneus (heel bone) angle (see Figure 6). As is illustrated in this figure, heel bone angles ranged from neutral (vertically aligned) to inverted (medially rotated). 


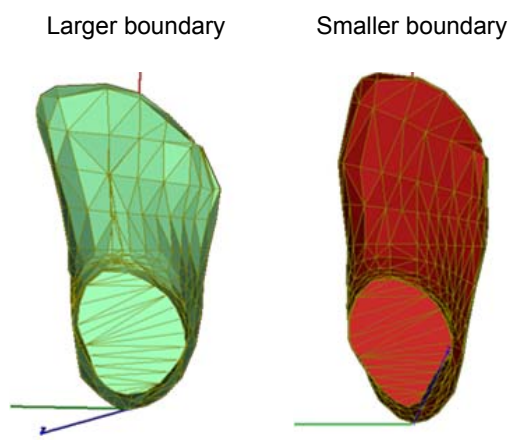

Fig. 4: PC Factor 1 shape identified by homologous modelling for females- toe box shape.

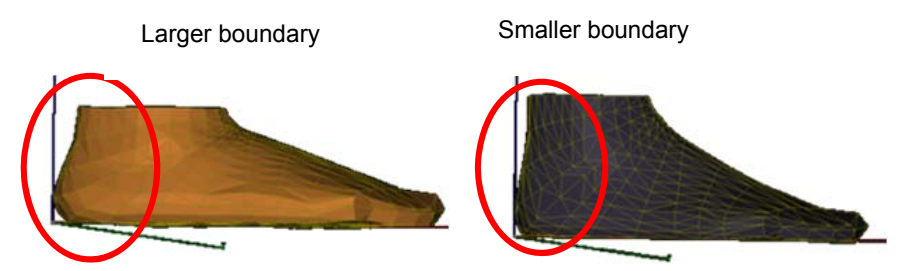

Fig. 5: PC Factor 2 shape identified by homologous modelling for females- heel shape.

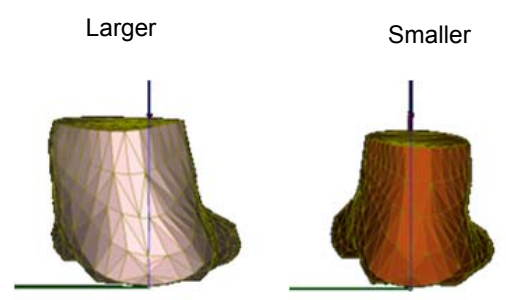

Fig. 6: Additional PC Factor 3 shape identified by homologous modelling for females- heel bone angle.

\section{Method}

\subsection{Initial last design and fit verification}

The identified foot shape variances, including foot width and height, heel-ball foot width ratio and to a lesser extent toe box shape were incorporated in the base size court shoe design. The base size for the SA females was identified to be a size 6 . The $1^{\text {st }}$ to $99^{\text {th }}$ percentile variance ranges were taken into consideration in the shoe design. All statistical analyses were conducted using STATISTICA $尺$ Software [19]. The design of the last to accommodate the foot variances of the SA females was conducted in the Shoemaster ${ }^{\mathrm{QS}}$ Custom software [18].

The shoe design and construction was fitted on a number of females to confirm the shoe size against the intended foot size range.

\subsection{Size grading and shoe styles}

The shoe size distribution within the SA female population was determined based on the traditional (one dimensional (1D)) anthropometric database consisting of data collected from 2000 to 2012, including approximately 2600 females. Recommendations for full and half size ranges were made to ensure accommodation of at least 90 percent of the females, and implemented in the grading of the court shoe 
lasts. Standard grading rules in accordance with the British size intervals for foot lengths $(7.62 \mathrm{~mm}$ foot length increments for full size) were used.

Two shoe styles were to be implemented. The purpose of evaluation of the two styles was two-fold: firstly, to investigate accommodation of the foot shape (heel-ball ratio and toe box shape) variances in two designs and secondly, to investigate the subjective preference of users between two court shoe styles implementing a higher versus lower heel height and a pointier versus rounder toe box shape.

\subsection{Objective fit and subjective comfort evaluation}

Participants volunteered to partake in the study. To ensure adequate representation of SA females, a minimum number of females per ethnic grouping and shoe size ranges were recommended.

Data collected per participant included right foot length and width measurements and three dimensional (3D) foot data (scans) of the left and right feet by means of an InFoot ${ }^{\mathrm{TM}}$ scanner [11]. The foot length measurements were used to prescribe the shoe size to be fitted by individuals. The 3D foot scans enabled identification and investigation of foot forms/shapes post the objective fit and subjective comfort evaluations. All participants' feet were scanned while wearing stockings (as worn with the court shoes). Fifteen anatomical landmarks were identified through palpation on each foot before scanning.

Fit guidelines for the objective evaluation of fit for the female court shoe were compiled based on the guidelines provided in the US Army technical manual [20]. The fit guidelines addressed four objective assessment areas including 1) arch support, 2) location of the ball joint in relation to shoe length, 3) ball of foot vs shoe width, and 4) foot length (adequate movement ease in front of toes). Factors influencing subjective comfort of footwear, such as form and density of the insole, form and fit of the shoe, and pressure distribution at different locations on the foot (planar, dorsal and lateral) $[22,6,17,23$, $15,2,14]$, were compiled in a perceptual questionnaire for subjective evaluation of fit.

Each participant was guided to fit the best size based on foot length measurements. The size selection process was controlled and participants were only allowed to deviate from the recommended size by a half size based on their personal preference. Participant were requested to wear the shoes for a minimum duration of 15 minutes during which they were requested to walk for a minimum distance of 500 meters which included level walking and climbing stairs. Following the 15 minutes wear time, the objective fit was evaluated followed by the administered perceptual comfort questionnaire.

\section{Results and Discussions}

\subsection{Initial last design and fit verification}

The foot width variance that had to be accommodated in the size 6 shoe was $79 \mathrm{~mm}$ to $105 \mathrm{~mm}$. This difference is too large to effectively be accommodated in one shoe, and the base size was thus focused on a medium width shoe size $(6 \mathrm{M})$. The percentile $\left(1^{\text {st }}\right.$ to $\left.99^{\text {th }}\right)$ ranges of foot dimensions to be accommodated in the size $6 \mathrm{M}$ female court shoe are provided in Table 1.

Table 1: Summary of foot dimension variation to be accommodated in the size 6M female court shoe.

\begin{tabular}{lccc}
\hline Foot dimensions & $\begin{array}{c}\mathbf{1}^{\text {st }} \\
\text { percentile }\end{array}$ & Mean & $\begin{array}{c}\mathbf{9 9}^{\text {th }} \\
\text { percentile }\end{array}$ \\
\hline Ball circumference & 205 & 232 & 265 \\
\hline Ball height & 33 & 39 & 43 \\
\hline Instep circumference & 211 & 227 & 247 \\
\hline Instep height & 48 & 66 & 81 \\
\hline Heel width & 52 & 64 & 77 \\
\hline Navicular height & 30 & 42 & 57 \\
\hline $\begin{array}{l}\text { Medial malleolus } \\
\text { height }\end{array}$ & 54 & 73 & 90 \\
\hline
\end{tabular}


Two iterations were completed where the shoe design and construction characteristics were verified against the foot size and shape variances intended to be accommodated in the size $6 \mathrm{M}$ court shoe. Sample sizes of females included in the fit evaluations ranged between 20 and 35 .

\subsection{Size grading and shoe styles}

The two styles of female court shoes included in the study are illustrated in Figure 7. The one design (Style A) had a seat width in accordance with the Shoe and Allied Trade Research Association (SATRA) guidelines for a size $6 \mathrm{l}$, a toe shape that was more pointy and a $45 \mathrm{~mm}$ heel height. The second design (Style B) had a wider seat width, rounder toe shape and $30 \mathrm{~mm}$ heel height. The two shoe styles were colored black and brown for the purpose of easy reference.
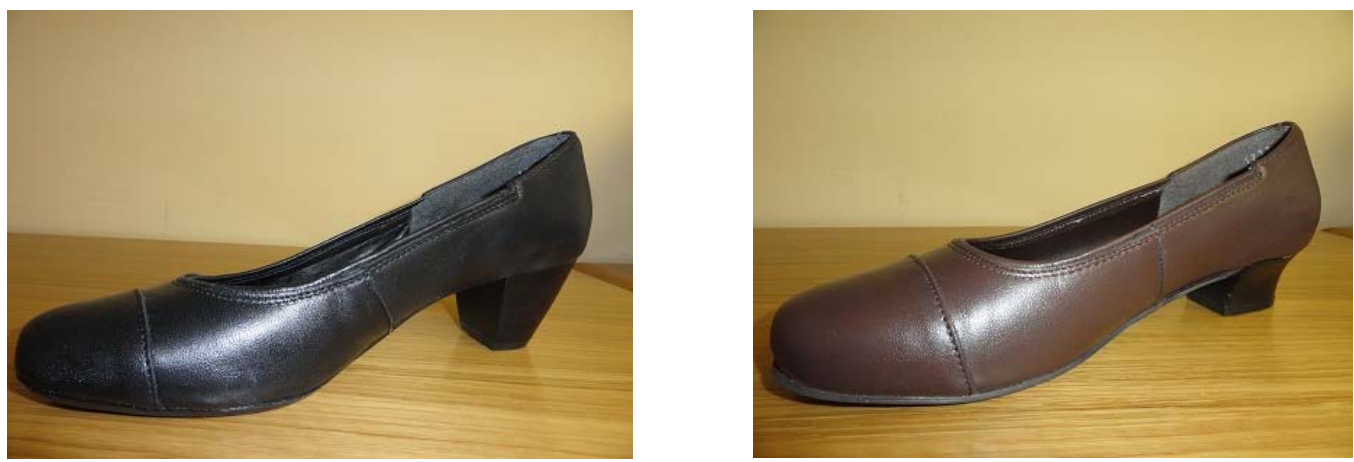

Fig. 7 : Court shoe style $A$ and style $B$

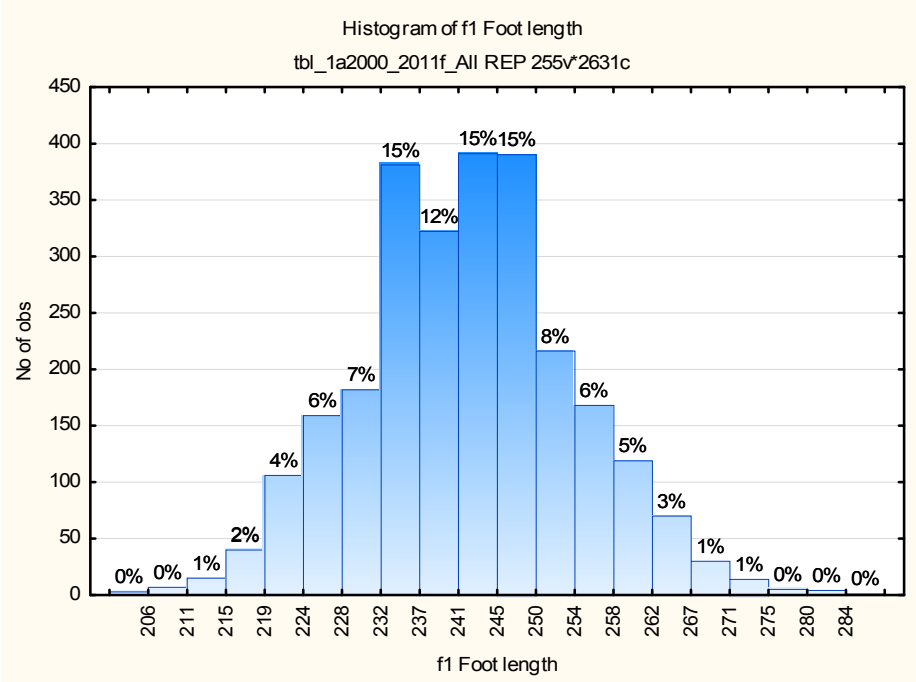

Fig. 8:Distribution of foot lengths within the SA female population [mm]

Figure 8 illustrates the distribution of foot lengths within the SA female population at half and full size intervals. Based on the distribution of foot lengths, it was recommended that shoe sizes be manufactured that could ensure accommodation of females with foot lengths between $215-219$ (size 3 ) to foot lengths between $267-271$ (size 9) to ensure accommodation of at least 90 percent of the females.

During the base size fit evaluation it was identified that a larger than expected accommodation of the foot width was observed in shoe style B. Due to this large foot width accommodation as well as the implementation of an additional shoe shape and style (Style A), only one fitting (width of shoe) was incorporated for further evaluation per full and half shoe size.

\subsection{Objective fit and subjective comfort evaluation}

A total of 252 females participated in the study. The distribution of foot lengths, grouped per shoe size, are summarised in Table 2. 
Table 2: Participants required for the female court shoe fit evaluation

\begin{tabular}{cccccc}
\hline $\begin{array}{c}\text { Shoe } \\
\text { size }\end{array}$ & African & Asian & Coloured & White & Total \\
\hline $\mathbf{2}$ & 1 & & & & 1 \\
\hline $\mathbf{3}$ & 18 & 2 & 8 & 5 & 28 \\
\hline $\mathbf{4}$ & 31 & & 1 & 10 & 37 \\
\hline $\mathbf{5}$ & 48 & 1 & 6 & 14 & 65 \\
\hline $\mathbf{6}$ & 51 & & 1 & 6 & 66 \\
\hline $\mathbf{7}$ & 30 & & & 4 & 36 \\
\hline $\mathbf{8}$ & 10 & 1 & & & 4 \\
\hline $\mathbf{9}$ & 4 & & & & $\mathbf{2 5 2}$ \\
\hline
\end{tabular}

The ranges of foot widths included in the fit and perceptual evaluation were assessed and good representation of the SA female population was observed during this fit evaluation (small $5^{\text {th }}$ and less percentile) and large (95 ${ }^{\text {th }}$ and larger percentile) foot widths were represented in the majority of shoe sizes (with exception of sizes 3, 8 and 9)).

During the fit evaluation, two foot form characteristics were identified which adversely affected the fit of the female court shoes, which included 1) arch height and 2) toe box shape (toe lengths). Foot forms associated with the arch height were classified into "flat feet" and "non-flat feet". "Flat feet" were identified as very low or no arch height, inverted calcaneous (heel) bone and accumulation of soft tissue on the medial side of the foot. Foot forms associated with toe box shapes were characterized by the toe lengths in relation to each other. Foot forms where the $1^{\text {st }}$ toe was longer than all other toes were labeled " 1 , where the $2^{\text {nd }}$ toes were as long or longer than the $1^{\text {st }}$ toes were labeled " 12 " and where the first 3 toes were of similar length and longer than remaining toes were labeled "123". Each individual's foot forms were classified into these two groups of foot forms during the fit and perceptual evaluation. The foot forms classified were furthermore verified following the fit evaluation by means of visual inspection of the 3D foot scans.

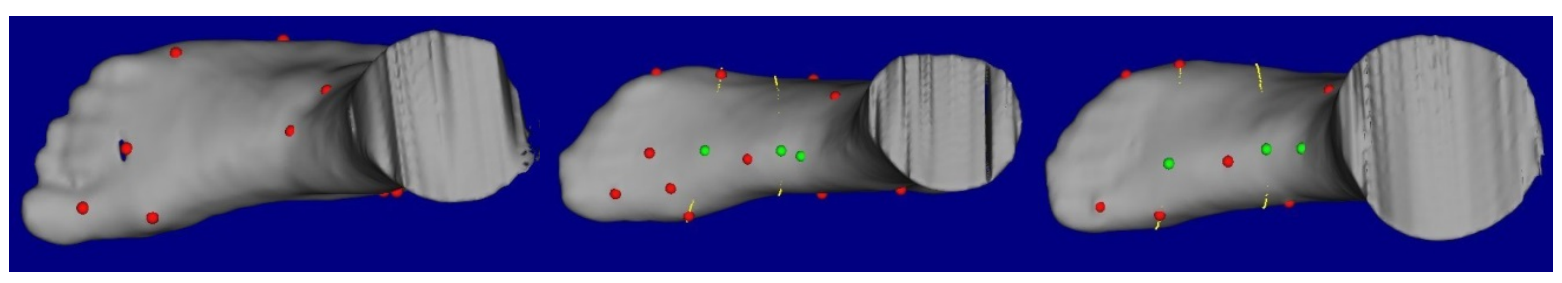

Fig. 9: Foot/toe form "1", "12" and "123"

Of the females that participated in the fit and perceptual evaluation, the largest percentage were observed to have "flat feet" (58\% in Figure 10$)$, and a similar percentage had the $1^{\text {st }}$ toe longest as well as the $1^{\text {st }}$ and $2^{\text {nd }}$ toes longest ( $42 \%$ in Figure 10 ).
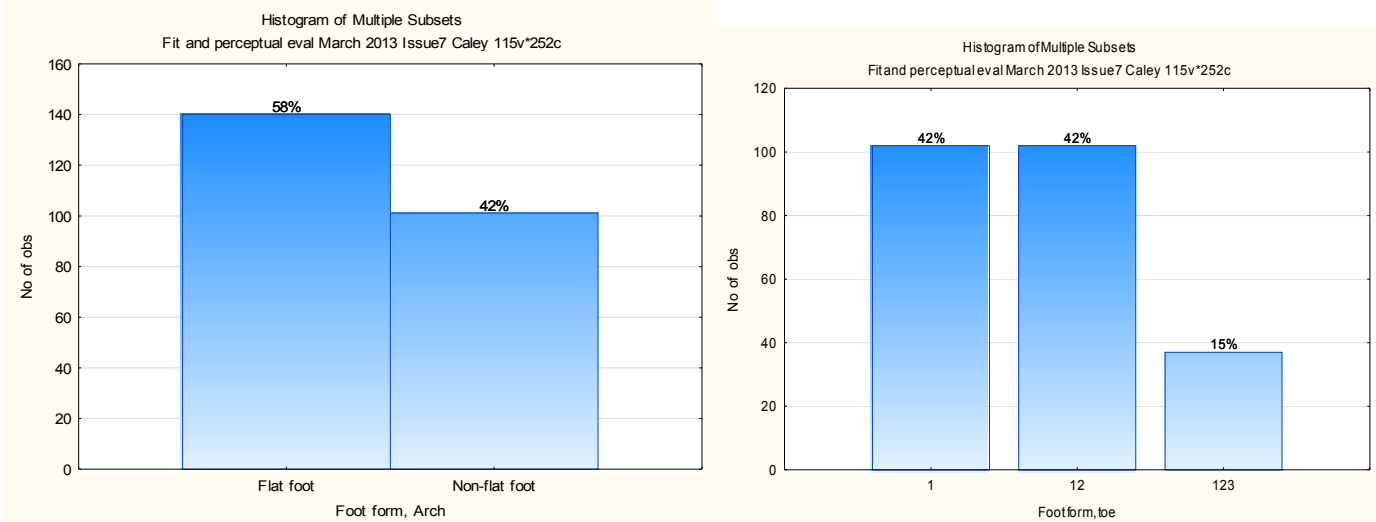

Fig. 10 : Percentage of foot forms observed for participants in fit and perceptual evaluation 
The objective fit results for the female court shoe style A resulted in poor fits due to insufficient support at the arch, medial and lateral support, and the shoe being too narrow at the heel, ball and toes, with the highest incidence of poor fits observed for females with flat foot forms (see Figure 11). No significant difference was observed between foot forms associated with toe box shape (Figure 12). Gaping of the shoe medially and laterally was observed and was associated with a seat width that is too narrow and poor arch support. The overall perception was similar to the objective fit with the majority of negative responses being related to insufficient support provided at the arches, space provided at the toes and the ball of the foot. The heel height was very positively perceived.

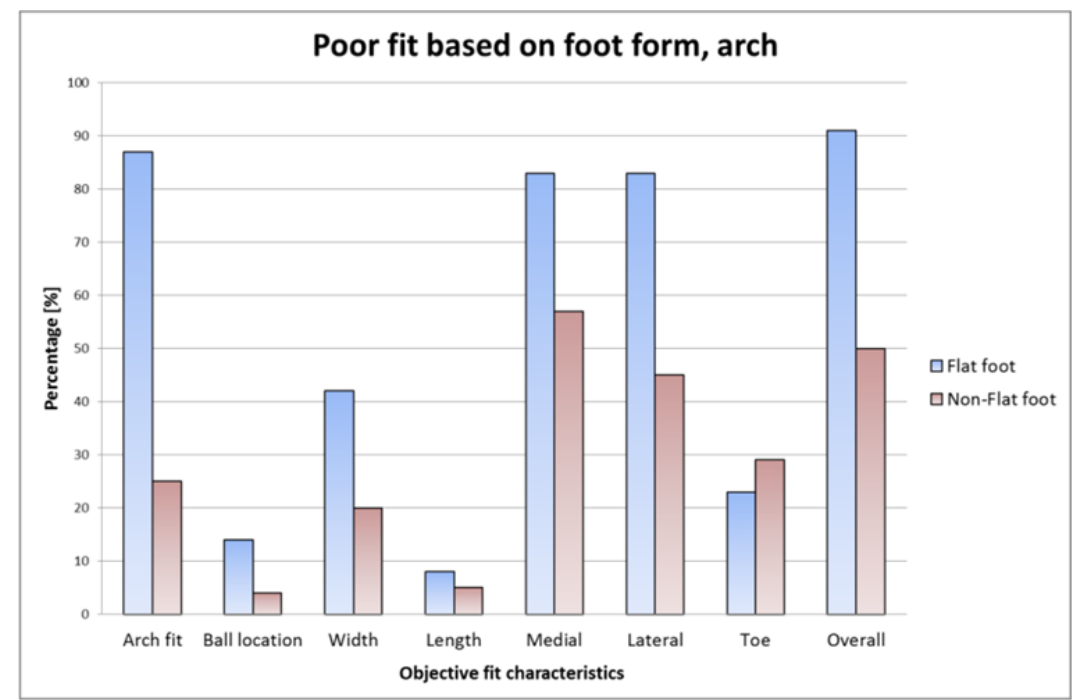

Fig. 11 : Percentage of poor fits for shoe style A per foot form, arch

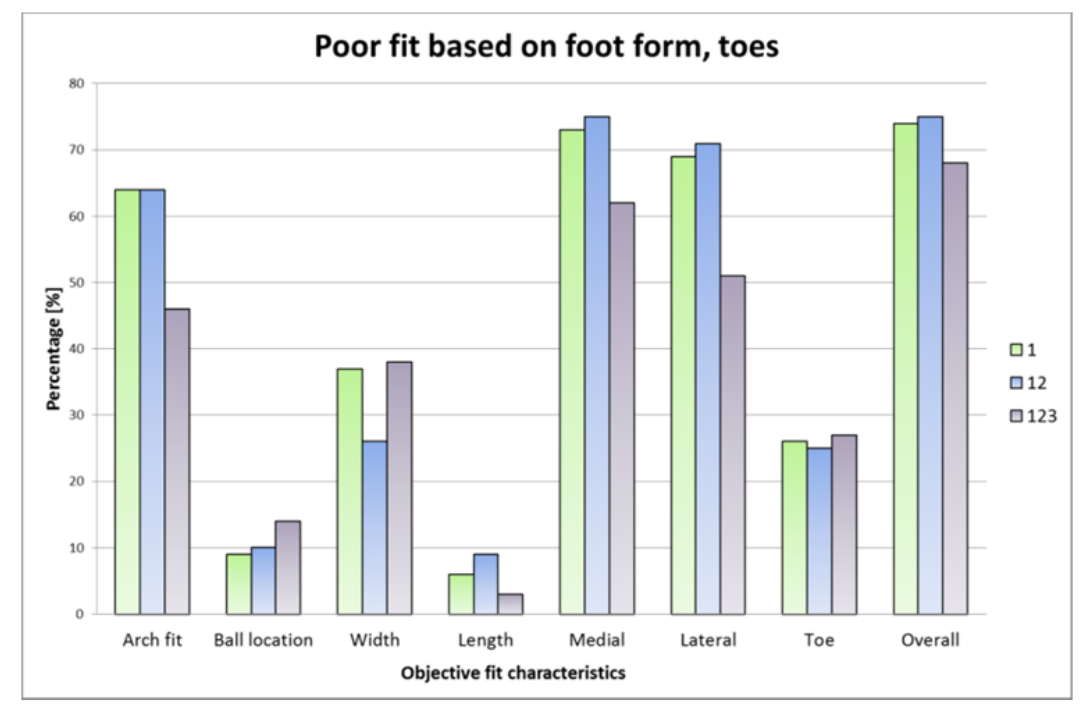

Fig. 12 : Percentage of poor fits for shoe style A per foot form, toes

The objective fit results for the female court shoe style $B$ indicated that more areas of acceptable fits were observed for court shoe style B than for style A. Areas of poor fit included only poor arch support and the shoe being too narrow for a few cases. The highest incident of poor fits was observed for females with flat feet (Figure 13). Marginally less poor fits were observed for females with the $1^{\text {st }}, 2^{\text {nd }}$ and $3^{\text {rd }}$ toes the longest (Figure 14). The overall perception of the female court shoe style B was also better than that for the female court shoe style A with the overall size, heel cushioning and the fact that the shoes do not slip out when the participant climbed stairs, perceived positive. The support provided at the arches of the foot, was insufficient for a relatively large percentage of the participants. The heel height was not overall positively perceived. 


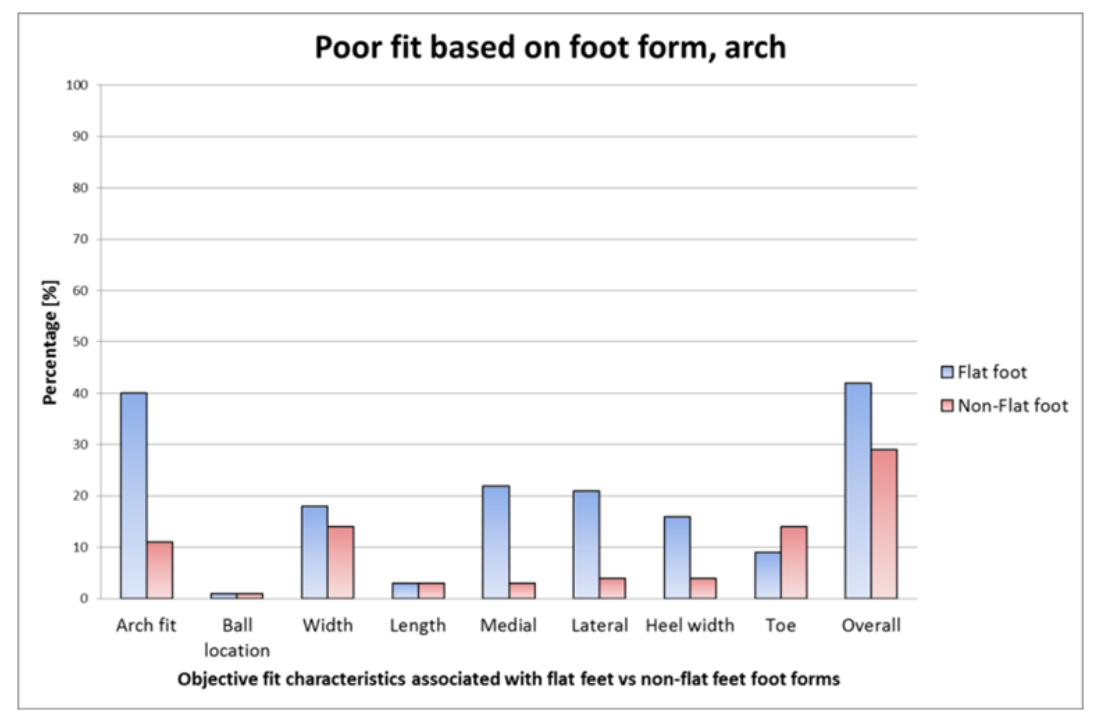

Fig. 13 : Percentage of poor fits for shoe style B per foot form, arch

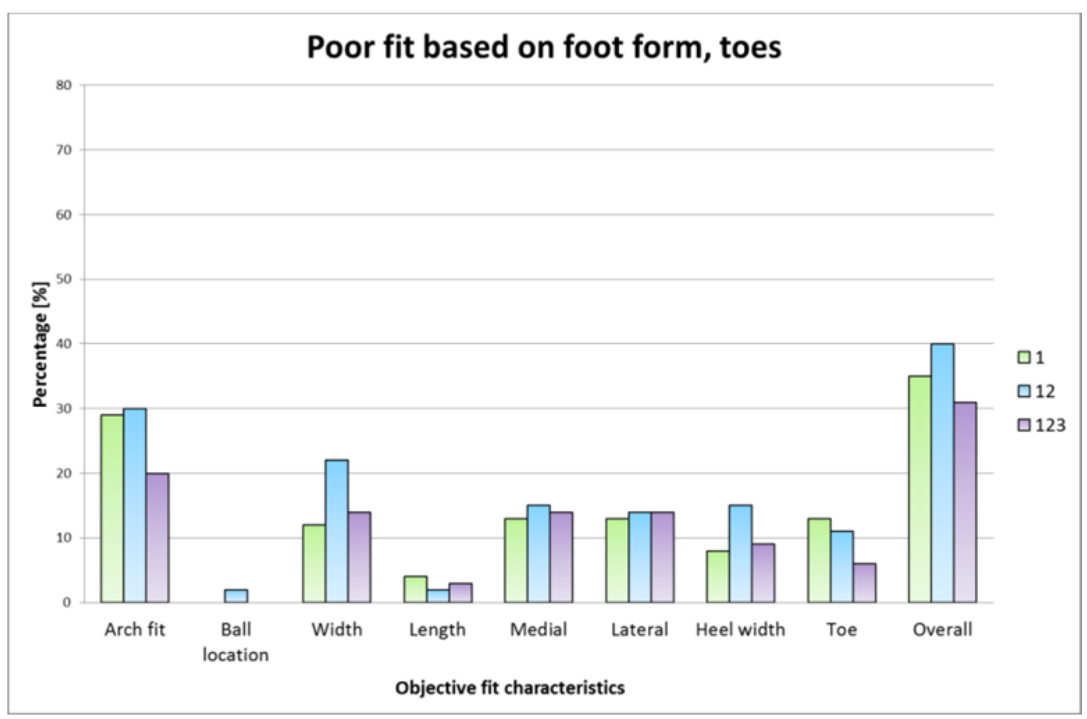

Fig. 14 : Percentage of poor fits for shoe style $B$ per foot form, toes

\section{Conclusions}

The court shoe style B, with a wider seat and rounder toe shape, obtained the overall better fit results compared to style A. The highest incidence of poor fits was observed for foot forms classified as "flat feet". For style A, poor fits were observed due to insufficient arch support (and medial and lateral gaping of the shoe), too narrow shoe width and insufficient toe space. For style $B$, poor fits were observed due to insufficient arch support. For style A, no difference in fit at the toe region of the shoe was observed for foot forms with different toe box shapes. For style B, marginally better fit for ladies with toe box foot forms classified as " $1^{\text {st }}, 2^{\text {nd }}$ and $3^{\text {rd }}$ toes longest" were observed.

Future investigations will incorporate style characteristics of both shoe styles: $45 \mathrm{~mm}$ heel height with toe shape that is slightly less pointy than style A but more pointy than style $B$. Two last designs will be incorporated: one with heel width similar to style $A$ and another with heel width similar to style B. Removable socks/footliners will be investigated with different arch heights to improve on support provided in the arch region. 


\section{References}

1. Alemany, S., Nacher, B., Gonzalez, J.C., Alcantara, E., Gomez, F., Montero, J., Vera, P. and Garcia, A.C., (2006): Prediction model of children footprints growing using geometric morphometric techniques. Proceedings of the International Ergonomics Association (IEA) Conference. Maastricht: IEA.

2. Au, E.Y.L. and Goonetilleke, R.S., ( 2007): A qualitative study on the comfort and fit of ladies' dress shoes. Applied Ergonomics, 38, 687-696.

3. Bataller, A., Alcantara, E., Gonzalez, J.C., Garcia, A.C. and Alemany, S., (2001): Morphological Grouping of Spanish Feet Using Clustering Techniques. Proceedings of the $5^{\text {th }}$ Symposium on Footwear Biomechanics. Zurich: Biomechanics Association.

4. Ben Azouz, Z., Roux, M., Shu, C. and Lepage, R., (2005): Characterizing Human Shape Variation Using 3-D Anthropometric Data. The Visual Computer International Journal of Computer Graphics, 22 (5) : 302-314.

5. Bredenkamp, K. and Skelton, S., (2009): Footwear Programme: Foot form characterisation and detailed footwear development plan. ERGOTECH Document P0837/2009/01. Centurion: ERGOnomics TECHnologies.

6. Curran, S.A., Holliday, J.L. and Watkeys, L., (2010): Influence of high heeled footwear and pre-fabricated foot orthoses on energy efficiency in ambulation. The Foot and Ankle Online Journal 3(3).

7. Frey, C., (2000): Foot health and shoe wear for women, Clinical orthopaedics, 372: 32-44.

8. Godil, A., (2007): 3D Shape representation and analysis of the human head and body. World Engineering Anthropometry Resource (WEAR) Conference proceedings. Banff: WEAR.

9. Gordon, C.C. and Brantley, J.D., (1997): Statistical Modeling of Population Variation in the Head and Face. Paper presented at The Design and Integration of Helmet Systems International Symposium. Boston, 3-5 December 1997.

10. Hudson, J.A., Zehner, G.F. and Meindl, R.S., (1998): The USAD multivariate accommodation method. Proceedings of the Human Factors and Ergonomics society (HFES) $42^{\text {nd }}$ annual meeting. USA: HFES.

11. I-Ware Laboratory Co., Ltd., (2005): INFOOT Operation Manual. I-Ware Laboratory Document no. IWL-CE-DC-IFU-03. Tokyo, Japan.

12. Krauss, I., Grau, S., Mauch M., Maiwald, C. and Horstmann, T., (2008) Sex-related differences in foot shap, Ergonomics, 51(11): 1693-1709.

13. Luo, G., Houston, V.L., Mussman, M., Garbarini, M., Beattie A.C. and Thongpop, C., (2009): Comparison of male and female foot shapes. Journal of American Podiatry Medicine Association 99(5): 383-390.

14. Mac Duff, L., (2006): Test methodology for the data capture of three dimensional (3D) foot scans. ERGOTECH Document P0608/2006/01. Centurion: ERGOnomics TECHnologies.

15. Miller, J.E., Nigg, B.M., Liu, W. and Stefanys, D.J., (2000). Influence of foot, leg and shoe characteristics on subjective comfort. Foot \& ankle International, 21 (9): 1-5.

16. Mochimaru, M. and Kouchi, M., (2007): Body shape browser based on homologous body modelling. World Engineering Anthropometry Resource (WEAR) Conference proceedings. Banff: WEAR.

17. Mundermann, A., Nigg, B.M., Stefanyshyn, D.J. and Humble, R.N., (2002). Development of a reliable method to assess footwear comfort during running. Gait and Posture, 16, 38-45

18. Shoemaster CSM3D International Limited., (2008): Shoemaster ${ }^{\text {QS }}$ CAD/CAM solutions for footwear design, development and manufacture. www.shoemaster.co.uk / www.torielli.com.

19. Statsoft Inc., (2011): Data Analysis Software System. www.statsoft.com

20. Veitch, D., Veitch, L. and Henneberg, M., (2007): Sizing for the Clothing Industry Using Principal Component Analysis - An Australian Example. Journal of ASTM International, 4(3).

21. TM 10-227, (2000): Technical Manual : Fitting of army uniforms and footwear. Headquarters, Department of the Army: Washington D.C.

22. Witana, C.P., Goonetilleke, R.S., Au, E.Y.L., Xiong, S. and Lu, X., (2009): Footbed shapes for enhanced footwear comfort. Ergonomics, 52 (5): 617-628.

23. Wunderlich, R.E. and Cavanagh, P.R., (2001): Gender differences in adult foot shape: implications for shoe design. Med. Sci. Sports Exerc 33(4): 605-611.

24. Yung-Hui, L. and Wei-Hsien, H., (2005): Effects of shoe inserts and heel height on foot pressure, impact force, and perceived comfort during walking. Applied Ergonomics, 36: 355-362. 